\title{
A fotografia como meio de apreensão da sociedade: uma experiência em Sociologia Ambiental
}

Lucas de Lima e Cunha

\section{RESUMO}

O presente trabalho relata uma experiência didática realizada durante o nosso estágio de docência em Sociologia, em uma instituição federal de ensino na cidade de Porto Alegre, no decorrer do ano 2018. A prática aqui relatada foi executada em duas turmas de Ensino Técnico. A disciplina ministrada em ambas as turmas foi a de Sociologia do Meio Ambiente e o recurso didático experimentado em sala de aula foi a fotografia como um meio de apreensão e apresentação do mundo social. Concluímos que fotografia é um excelente recurso para estimular nos estudantes o modo de ver sociológico.

Palavras-Chave: Sociologia; Meio Ambiente; Fotografia.

\begin{abstract}
The present study report a didactic experience performed during our teaching internship in sociology, in a federal educational institution in the city of Porto Alegre, during the year 2018. The practice reported here was carried out in two classes of Technical Education. The discipline taught in both classes was the Sociology of the Environment and the didactic resource experienced in the classroom was photography as a means of apprehension and presentation of the social world. We conclude that photography is an excellent resource to stimulate in students the sociological way of seeing.
\end{abstract}

Key-Words: Sociology; Environment; Photography.

\footnotetext{
${ }^{1}$ Bacharel e Licenciado em Ciências Sociais e Mestre e Doutor em Sociologia pela Universidade Federal do Rio Grande do Sul (UFRGS). E-mail: lucascunha79@yahoo.com.br.
} 


\section{PRÓLOGO}

$\mathrm{O}$ trabalho a seguir discorreu sobre uma experiência didática realizada durante o nosso estágio de docência em Ciências Sociais, no decorrer do ano de 2018. Essa experiência foi executada em duas turmas de Ensino Técnico de uma instituição federal na cidade de Porto Alegre: uma do Curso de Técnico em Administração na modalidade $\mathrm{PROEJA}^{2}$ e a outra do Curso de Técnico em Meio Ambiente. A disciplina ministrada para ambas as turmas foi a de Sociologia Ambiental e um dos recursos didático empregado foi o registro fotográfico, realizado pelos próprios estudantes, como uma forma de estimular o modo de ver sociológico.

O texto a seguir foi dividido em três seções: a introdução, dividida em duas partes. A primeira discutindo, de forma breve, as diferentes possibilidades sociológicas de apreendermos as sociedades e a segunda justificando teoricamente o porquê do emprego da fotografia como uma das formas de apreensão e apresentação do mundo social; o relato propriamente dito da experiência em ministrar uma disciplina de Sociologia do Meio Ambiente, também dividido em duas partes. A primeira concernente às definições teóricas acerca da Sociologia do Meio Ambiente e às determinações legais da Educação Ambiental e a segunda referente aos resultados obtidos em sala de aula; e, por fim, as considerações finais.

Dito isso, o objetivo desse trabalho foi relatar uma experiência realizada em uma disciplina de Sociologia do Meio Ambiente envolvendo a fotografia como um dos possíveis recursos didáticos a ser empregado em sala de aula. Sendo assim, foge das intenções desse

\footnotetext{
${ }^{2}$ Programa Nacional de Integração da Educação Profissional com a Educação
} Básica na Modalidade de Educação de Jovens e Adultos. 
ensaio o aprofundamento teórico, metodológico e epistemológico das questões relacionadas à fotografia, ao meio ambiente e ao ensino de Sociologia. Em outras palavras, o texto a seguir buscou articular essas três dimensões - fotográficas, ambientais e didáticas - em um único relato de cunho sociológico, ${ }^{3}$ conforme veremos abaixo.

\section{Introdução}

Provavelmente tenha sido o tcheco Jan Amos Komenský (ou Comenius, na forma ocidentalizada) um dos primeiros educadores a perceber a importância das imagens para o aprendizado das crianças. Em meados do século XVII, o referido autor publicou aquele que ficou conhecido como o primeiro livro ilustrado para crianças: Orbis Sensualium Pictus (O Mundo Sensível em Imagens) - também chamado de Orbis Pictus (O Mundo Visível). Nesse pequeno livro, Comenius utilizou 150 imagens, e suas correspondentes nomenclaturas e descrições, para representar "as principais coisas do mundo e o emprego que os seres humanos fazem delas" (COMENIUS, 1887, p. xiv, tradução nossa).

Para Comenius (1887), as imagens seriam as representações de todas as coisas visíveis, e mesmo as invisíveis, existentes no mundo. Já as nomenclaturas seriam as inscrições ou títulos que definem suas imagens correspondentes e que expressam aquelas coisas presentes no mundo em seus próprios termos gerais. Por fim, as descrições seriam as explicações das imagens expressas por seus próprios termos. Isso significa que, para Comenius, o aprendizado das palavras de nada serviria se essas

\footnotetext{
${ }^{3}$ Primeiro porque esse texto foi pensado ao longo da disciplina de Sociologia por nós ministrada, o que nos garantiu um relativo estoque de conhecimento acerca das temáticas aqui relatadas e, segundo, porque existem outras áreas do conhecimento passíveis de fornecer subsídios teóricos, metodológicos e epistemológicos para o desenvolvimento de uma tarefa semelhante a nossa. Pensemos, por exemplo, na Antropologia, na Educação Artística ou na Biologia.
} 
estivessem separadas das suas respectivas imagens, da mesma forma que as imagens nada representariam se não fossem descritas por palavras. ${ }^{4}$ Logo, palavras e imagens seriam complementares de acordo com o educador tcheco, ou seja, uma não faria sentido sem a outra e vice-versa, sobretudo durante as primeiras fases do aprendizado infantil. E por que as imagens? Porque Comenius acreditava que dessa forma as crianças não achariam um tormento ir à Escola, mas, sim uma tarefa prazerosa, uma vez que as crianças, mesmo as mais novas, se deleitam com imagens, pois elas agradam os seus olhos (COMENIUS, 1887).

Mutatis mutandis, a Sociedade é um fenômeno bastante complexo e diversificado, de modo que o melhor é nos referirmos às sociedades ou aos grupos sociais que as compõem. Diante de tamanha complexidade e diversidade, as sociedades possibilitam diferentes formas de apreensão e apresentação, tanto por parte dos sociólogos de forma específica, quanto dos estudantes de Sociologia em geral. Em outras palavras, podemos conhecer as sociedades, nos informar acerca delas e ensinar algo sobre elas através de variados meios: observando, ouvindo, descrevendo, contando, etc.

Conforme o sociólogo norte-americano Howard Becker é possível falar das, representar as, sociedades a partir de diferentes métodos de análises, tais como: descrições etnográficas; tipos ideais; filmes documentais; tabelas e gráficos estatísticos; diagramas; romances; e a fotografia (BECKER, 2009). Vale dizer que nenhum desses métodos é melhor, ou descreve as sociedades de forma mais fidedigna, do que os outros. Aqui, a escolha vai depender dos objetivos da pesquisa, das

4 É digno de nota chamar a atenção para o fato de que a relação complementar entre escrita e imagem permanece viva até hoje nos debates acadêmicos. Por exemplo, Samain (200o), ao analisar algumas fotografias da seminal monografia de Antropologia Visual elaborada por Gregory Bateson e Margaret Mead sobre a personalidade balinesa, de 1942, afirma que a escrita indica e define aquilo que a imagem - no caso, a fotografia - é incapaz de mostrar, e a imagem mostra aquilo que a escrita é incapaz de enunciar claramente (SAMAIN, 2000). 
fontes e acessos das informações disponíveis e também da originalidade do pesquisador em descrever uma sociedade ou parte dela.

Além disso, e ainda conforme Becker (2009), as representações que fazemos das sociedades, o modo que falamos delas, não possuem significado fixos, visto que essas representações variam conforme o contexto social em que elas são empregadas. Isso significa que, por exemplo, uma mesma imagem poderá assumir diferentes significados conforme os diferentes contextos onde ela será apresentada: em um jornal; em uma galeria de arte; num álbum de família; ou em sala de aula. Além dessa polissemia, as fotografias podem ser utilizadas de diversas maneiras nas pesquisas sociais, como, por exemplo, fonte documental, dado de pesquisa, documento memorialístico ou meio de reconstrução histórica de uma dada época (FERNANDES, 2011). Diante dessas constatações percebemos que existem diversas possibilidades para o uso da fotografia, e uma delas é utilizá-las como um meio de apreensão e apresentação da Sociedade nas escolas e demais instituições de ensino.

Escolhemos nesse trabalho a fotografia como meio de apreensão da Sociedade, ou melhor, como um instrumento de prática didática da Sociologia, por diversos motivos conforme discutiremos a seguir. Ademais, acrescentamos que essa prática não se restringe apenas ao ensino de Sociologia. Acreditamos que ela pode ser empregada - da mesma forma que aqui a discutimos - nas demais disciplinas escolares e acadêmicas. Todavia, conforme já dito, restringiremos nossa explanação no âmbito exclusivo da Sociologia.

Atualmente, podemos dizer que as câmeras fotográficas estão ao alcance de quase todos os indivíduos, sobretudo entre os jovens, através 
do uso de aparelhos de telefones celular, o que torna o recurso fotográfico acessível para qualquer pessoa. ${ }^{5}$ Isso tanto é verdade que, conforme os dados da ANATEL (Agencia Nacional de Telecomunicações, 2018), em Agosto de 2018 havia em todo território nacional mais de 234 milhões de linhas móveis em operação, para uma população de um pouco mais de 209 milhões de brasileiros (INSTITUTO BRASILEIRO DE GEOGRAFIA E ESTATÍSTICA, 2018).

Diante da proporção de acessos a recursos fotográficos, da instantaneidade das fotografias proporcionada pelas tecnologias digitais e do baixo custo econômico, podemos dizer que a prática fotográfica deixou de ser, em certa medida, solene, cerimonial e voltada à coesão social (BOURDIEU, 2003) e passou a ser uma prática fugaz, experimental e individual - vide as selfies. Em outras palavras, a fotografia na era digital não perdeu sua função social de manter a integração dos grupos sociais (familiares, profissionais e amistosos) através do registro dos ritos da vida coletiva (casamentos, nascimentos, festas, reuniões, viagens, etc.) como diria Bourdieu (2003), todavia, gradativamente a fotografia tem se tornado um objeto mais virtual do que real. Já não existem mais tantos quadros e porta-retratos nas casas e cada vez menos as fotografias são guardadas em caixas nos armários. A fugacidade da fotografia na era digital torna-a altamente reprodutível, manipulável e descartável. Por sua vez, tais características permitem o experimentalismo da prática fotográfica, uma vez que não se corre mais o risco de "queimar o filme", nem de se desperdiçar mais tanto dinheiro e tempo para revelar as fotos, visto que as câmeras digitais possibilitam a instantaneidade da foto tirada. Por fim, por se tornar, também, cada vez mais uma prática individual, a fotografia deixou de registrar apenas certos objetos e

${ }^{5}$ Bourdieu (2003) já chamava a atenção para esse fato em 1965, ao lembrar que a acessibilidade e a simplicidade do manuseio das câmeras fotográficas eram fatores que ajudavam a explicar a difusão da atividade fotográfica em quase todos os estratos sociais. 
determinadas ocasiões e passou a registrar quase todos os objetos e ocasiões de acordo com as preferências pessoais e possibilidades situacionais do fotógrafo. Nesse sentido, podemos dizer que, na era digital, aquilo que a fotografia perdeu em objetividade, ela ganhou em subjetividade.

Outro motivo para utilizarmos o ato fotográfico como um instrumento de prática didática nas aulas de Sociologia, diz respeito ao fato de que a fotografia é uma forma de conhecimento visual do mundo social e ato de fotografar um modo de construção e de registro da realidade desse mundo (MARTINS, 2009). Além disso, a fotografia é também um dos componentes do funcionamento da Sociedade Moderna (ou pós-Moderna, como queiram) "intensamente visual e dependente da imagem", algo que a torna um objeto de informação e de interpretação dessa sociedade (MARTINS, 2009, p. 36). Do ponto de vista individual, Freund (1993) diria que as imagens fotográficas corresponderiam à necessidade das pessoas em expressarem suas individualidades e o ato de registrar essas imagens seria uma forma de exteriorização dos seus sentimentos, tal como uma "espécie de criação" (FREUND, 1993, p. 9).

Até aqui podemos extrair duas importantes potencialidades da fotografia e do ato fotográfico como recursos didáticos no ensino de Sociologia. O primeiro seria aquele de recorrer às fotografias como fontes documentais a serem analisadas posteriormente pelos sociólogos (BODART, 2015). Nesse sentido, podemos pensar nas fotografias como “verdadeiros sociogramas” que permitem aos sociólogos interpretar um determinado ponto de vista acerca das relações e situações que compõem as sociedades (BOURDIEU; BOURDIEU, 2015, p. 34). Aqui, importa menos as qualidades técnicas e estéticas das fotografias e mais o registro das condutas socialmente aprovadas e reguladas pelos grupos sociais que fotografam e que são fotografados (BOURDIEU, 2003). 
A segunda maneira de utilizar a fotografia como um recurso didático para o ensino de Sociologia, ainda de acordo com Bodart (2015), seria através do próprio ato de fotografar, pensado aqui como uma forma de produção e coleta de dados e informações para as análises sociológicas. Nesse sentido, segundo Martins (2009), a fotografia equivaleria e complementaria outras técnicas de investigação social, tais como os questionários, as entrevistas, os diários de campo, etc. Aqui, haveria uma certa necessidade técnica na hora de capturar as imagens, visto que deve existir uma "intencionalidade sócio-estética por parte do sociólogo-fotógrafo" (BODART, 2015, p. 85). Isso quer dizer que, enquanto uma técnica de pesquisa, o ato de fotografar deve ser ajustado ao modo de ver sociológico que busca visualizar - isto é, entender - o lugar das coisas em "uma ordem dotada de significados" sociais (BAUMAN; MAY, 2010, p. 187).

Aqui cabe abrir um parêntese. Pensada como uma técnica, poderíamos criar uma interface com a Educação Artística, e ensinar aos estudantes os recursos técnicos e os elementos estéticos do ato de fotografar, tais como o foco, a luminosidade, a textura, o movimento, a profundidade, a perspectiva, etc. que ajudam a realçar, ou ofuscar, determinados detalhes da imagem registrada. Sem dúvidas que essa interface com a Educação Artística tornaria as fotografias muito mais ricas em termos técnicos e estéticos, ${ }^{6}$ todavia, suspeitamos que tais atributos tornariam as fotografias registradas menos espontâneas e mais artificiais por assim dizer.

O terceiro motivo para utilizarmos o ato fotográfico como um instrumento de prática didática nas aulas de Sociologia, diz respeito ao fato de que as imagens capturadas pelas lentes dos aparelhos de telefone

\footnotetext{
${ }^{6}$ Lembrando que fotografia também pode ser pensada como uma forma de arte, isto é, dotada de uma aura artística, como "uma figura singular, composta de elementos espaciais e temporais: a aparição única de uma coisa distante, por mais próxima que ela esteja" (BENJAMIN, 1987, p. 101).
} 
celular propiciam o exercício daquilo que Mills (1982) designava como “imaginação sociológica” por parte dos estudantes. Em outras palavras, a partir das representações visuais retratadas pelos alunos e alunas, é possível, acreditamos, estimular aquela:

(...) qualidade de espírito que lhes ajude a usar a informação e a desenvolver a razão, a fim de perceber, com lucidez, o que está ocorrendo no mundo e o que pode estar acontecendo dentro deles mesmos (MILLS, p. 11, 1982).

Com isso Mills (1982) queria dizer que a imaginação sociológica proporciona o entendimento das realidades mais íntimas das consciências individuais associadas às estruturas mais amplas da realidade sociohistórica das sociedades. Em outras palavras, a imaginação sociológica permite compreendermos a Sociedade - a nossa sociedade, - partir dos seus significados para a vida íntima dos indivíduos. Aqui, o indivíduo vê-se a si mesmo no entorno social no qual ele se desenvolve, conectando aquilo que é imediatamente vivido por ele aos acontecimentos históricos da sua época (CUSICANQUI, 2015).

Mais três motivos reforçam o emprego do ato fotográfico, e das fotografias, como um meio de apreensão das sociedades: 1) como bem lembrou Bodart (2015) há, cada vez mais, uma preocupação com o desenvolvimento de recursos didáticos que tornem as aulas no Ensino Básico mais dinâmicas e atrativas para os estudantes. Para o ensino de Sociologia essa preocupação é mais acentuada devido à inconstância da disciplina no currículo nacional, algo que impede o desenvolvimento e a consolidação de recursos didáticos adequados a esse ensino. Acreditamos que a fotografia, bem como o ato de fotografar, seja um desses recursos atrativos para o ensino de Sociologia no Ensino Médio; 2) exercícios envolvendo práticas fotográficas podem extrapolar o ambiente escolar e fazer com que os estudantes saiam às ruas e fotografem a realidade ao seu redor; e, por fim, 3) as fotografias 
registradas pelos estudantes podem servir de material para a composição das aulas de Sociologia, tornando-os, com isso, protagonistas ativos da prática didática e não meros espectadores em sala de aula.

\section{Uma experiência fotográfica em Sociologia do Meio Ambiente}

A seguir descreveremos os procedimentos tomados para realizar uma atividade envolvendo o uso de fotografia em uma disciplina de Sociologia do Meio Ambiente. Conforme dito, tal atividade foi realizada durante o nosso estágio de livre docência em uma instituição federal de ensino localizada em Porto Alegre, com duas turmas de Ensino Técnico, uma do curso de Técnico em Administração na modalidade PROEJA e outra do curso de Técnico em Meio Ambiente, no decorrer do ano de 2018. Acreditamos que essa atividade pode ser empregada em qualquer outro ramo da Sociologia, bem como em outras disciplinas, uma vez que a intenção principal é fazer com que os estudantes visualizem, representem e interpretem as sociedades por meio de registros fotográficos e do seu produto final, a fotografia.

Em termos gerais, a Sociologia do Meio Ambiente - ou Sociologia Ambiental - versa sobre a interação entre fenômenos sociais e ambientais (CATTON; DUNLAP, 1978) ou, se preferirmos, entre a relação Sociedade/Natureza. Tal interação pode ser percebida das mais variadas formas como, por exemplo, uma floresta desmatada, um rio poluído, um solo erodido, uma vegetação contaminada, acúmulos de lixo descartados de forma incorreta em locais proibidos, etc.

É importante frisar que a Sociologia Ambiental não é sinônimo de Educação Ambiental, ainda que a primeira possa fazer parte do currículo dessa última. Inicialmente a Educação Ambiental foi definida por lei no Brasil como: 
(...) os processos por meio dos quais o indivíduo e a coletividade constroem valores sociais, conhecimentos, habilidades, atitudes e competências voltadas para a conservação do meio ambiente, bem de uso comum do povo, essencial à sadia qualidade de vida e sustentabilidade. (E como) um componente essencial e permanente da educação nacional, devendo estar presente, de forma articulada, em todos os níveis e modalidades do processo educativo, em caráter formal e não-formal (BRASIL, 1999, arts.1으 e $2^{\circ}$ ).

Por seu turno, a Sociologia do Meio Ambiente é um ramo da Sociologia que surgiu no final dos anos 60 e início dos anos 70 nos Estados Unidos, período esse marcado por uma série de movimentos sociais, não apenas nos EUA, como em diversos países do mundo, inclusive no Brasil. Esses movimentos reivindicavam por igualdade racial, igualdade de gênero, por direitos civis igualitários, pela pacificação e pela preservação ambiental. Além disso, nessa época, tornava-se cada vez mais explícita a relação nefasta entre o desenvolvimento industrial, sobretudo nos países ricos, e a degradação dos recursos naturais, sobretudo nos países pobres, bem como se tornavam cada vez mais visíveis os problemas da poluição ambiental causados pela industrialização (FERREIRA; FERREIRA, 2002).

Diante do cenário acima descrito e da intensificação da degradação ambiental, sociólogos norte-americanos de diferentes subcampos da Sociologia começaram a perceber que havia uma estreia relação entre fenômenos naturais e fenômenos sociais, e a estudar os efeitos produzidos pelas sociedades no meio ambiente e os efeitos do meio ambiente sobre as sociedades, como, por exemplo, o impacto de diferentes sistemas econômicos sobre a degradação ambiental ou a influência da abundância ou escassez de recursos sobre a estratificação social (CATTON; DUNLAP, 1978). O que ocorreu aqui foi uma mudança de ponto de vista sociológico que, até então, priorizava explicar de modo bem durkheimiano o social pelo social e negligenciava os fenômenos 
biológicos e ecológicos da existência humana como variáveis explicativas dos fenômenos sociais (BUTTEL, 1992).

Vale dizer que tal "negligência" é bastante compreensível, visto que os sociólogos clássicos tinham como um dos seus objetivos demarcar um campo de estudo distinto das ciências naturais. Uma das consequências dessa distinção foi a autonomização dos fenômenos sociais em relação aos fenômenos naturais e a desconsideração das questões ambientais como fatores explicativos das condições sociais (ALONSO; COSTA, 2002).

A mudança de ponto de vista acima mencionada também pode ser entendida como uma mudança de paradigma no campo sociológico. Em outras palavras, na Sociologia Tradicional tínhamos o "paradigma da excepcionalidade humana”, norteado por uma visão antropocêntrica das sociedades, que considerava os seres humanos como criaturas singulares no Planeta Terra que possuem Cultura e que, por isso, eram capazes de progredir ilimitadamente e ao mesmo tempo controlar, solucionar e reverter os problemas sociais e ambientais causados por esse progresso através do desenvolvimento científico e tecnológico acumulado culturalmente ao longo do tempo. Já com o advento da Sociologia do Meio Ambiente surge um "novo paradigma ambiental", com uma visão ecocêntrica das sociedades, que considerava os seres humanos como apenas uma das muitas espécies que vive de maneira interdependente com os demais seres vivos no Planeta. Aqui são consideradas as consequências involuntárias geradas no meio ambiente pelas ações sociais intencionais e a relação retroalimentativa entre ambas, bem como o fato de que os recursos naturais são finitos e de que o progresso social é limitado em razão das potencialidades físicas e biológicas do Meio Ambiente (CATTON; DUNLAP, 1978; BUTTEL, 1992).

Devido as suas raízes interdisciplinares, a Sociologia do Meio Ambiente possui um vasto leque de opções de objetos de pesquisa. 
Dentre eles podemos destacar os estudos voltados: 1) às atitudes, valores, percepções e comportamentos em relação ao Meio Ambiente, isto é, como as pessoas percebem a Natureza e como elas interagem com o Meio Ambiente ao redor; 2) aos movimentos sociais ambientalistas, tais como as ONGs, fundações e associações ecológicas, tanto em uma escala regional, quanto global; 3) às políticas ambientais, como os tratados, conferências e protocolos nacionais e internacionais; 4) aos desastres e riscos ambientais característicos das sociedades contemporâneas; 5) aos conflitos ambientais; 6) aos direitos e as leis ambientais; e 7) às noções de Educação, Economia; Justiça e Saúde ambientais (HERCULANO, 2000; ALONSO; COSTA, 2002; FERREIRA; FERREIRA, 2002). Notamos com esses exemplos que a Sociologia Ambiental é bastante diversificada, bem como permite explorar diferentes dimensões da relação recíproca entre Sociedade e Natureza.

Por fim, é interessante notar que, conforme a resolução das diretrizes curriculares nacionais de 2012, a Educação Ambiental passou a ser definida como:

(...) uma dimensão da educação, (uma) atividade intencional da prática social, que deve imprimir ao desenvolvimento individual um caráter social em sua relação com a natureza e com os outros seres humanos, visando potencializar essa atividade humana com a finalidade de torná-la plena de prática social e de ética ambiental. (Que) visa à construção de conhecimentos, ao desenvolvimento de habilidades, atitudes e valores sociais, ao cuidado com a comunidade de vida, à justiça e à equidade socioambiental, e à proteção do meio ambiente natural e construído. (...) construída com responsabilidade cidadã, na reciprocidade das relações dos seres humanos entre si e com a natureza. (E que) deve adotar uma abordagem que considere a interface entre a natureza, a sociocultura, a produção, o trabalho, o consumo (BRASIL, 2012, arts. $2^{\circ}, 3^{\circ}, 4^{\circ} \mathrm{e} 6^{\circ}$ ).

Percebemos que essa nova definição de Educação Ambiental além de ser mais ampla e refinada do que aquela elaborada em 1999 - 
aproxima-se muito daquelas concepções elaboradas pelos sociólogos americanos para definir o que veio a ser conhecido como Sociologia do Meio Ambiente. Apenas não sabemos precisar, ou mesmo afirmar, o quanto aquela definição foi influenciada por essas concepções. O que sabemos ao certo é que, conforme as Diretrizes Curriculares Nacionais para o Ensino Médio, instituídas pelo Ministério da Educação no ano 2012, a oferta e a organização do Ensino Médio no Brasil, entre outros, devem ser baseadas na:

(...) sustentabilidade socioambiental como meta universal, desenvolvida como prática educativa integrada, contínua e permanente, e baseada na compreensão do necessário equilíbrio e respeito nas relações do ser humano com seu ambiente (BRASIL, 2012a, arto $13-\mathrm{V}$ ).

Tal diretriz, ao corroborar a pertinência temática da Educação Ambiental no Ensino Médio, acaba por reforçar a necessidade do ensino de Sociologia nas escolas ao levar em conta a relevância da atividade humana em relação ao ambiente, seja ele social ou natural.

Essa breve discussão acerca do que é Educação Ambiental e das definições e objetos de pesquisa da Sociologia Ambiental é necessária, pois, antes de sair por aí e fotografar aleatoriamente a realidade social, é necessário compreender o papel da teoria e sua importância para acessarmos essa realidade. Isso por dois motivos: $1^{\circ}$ ) o uso da fotografia, assim como outras técnicas de pesquisa, possui suas limitações analíticas; e 2º) tanto os sociólogos, quanto os estudantes de sociologia e as pessoas de modo geral - possuem visões de mundo particulares e valores sociais próprios (FERRO, 2015). E como bem sabemos, uns dos papéis centrais da Sociologia no Ensino Médio é provocar a desnaturalização e o estranhamento dos estudantes acerca da naturalização dos fenômenos sociais e da familiaridade de suas 
respectivas realidades sociais (BRASIL, 2006). E como fazemos isso? Através das teorias sociológicas.

Com isso queremos dizer que é preciso:

(...) formular a pergunta de partida, definir rigorosamente o objecto de estudo, trabalhar a problemática teórica, desenhar o modelo de análise, etc., antes de fotografar (FERRO, 2015, p. 381).

Lembrando que essa afirmação não exclui o uso da fotografia (e dos registros fotográficos) como uma técnica complementar bastante frutífera para as análises exploratórias de estudos e pesquisas. Todavia, ainda assim, será sempre a teoria que determinará a relevância sociológica da informação registrada pela fotografia (FERRO, 2015).

A partir das discussões em sala de aula acerca das principais definições e objetos de análise concernentes à Sociologia Ambiental, é possível solicitar aos estudantes que fotografem, em seus cotidianos, aquelas interações percebidas por eles entre fenômenos sociais e fenômenos ambientais ou, se preferirmos, entre Sociedade e Natureza. Apesar de parecer algo relativamente simples de ser feito, percebemos durante a realização da atividade que, por um lado, os estudantes se mostram animados com uma tarefa fotográfica, pois isso estimula o papel ativo deles em sala de aula, bem como suas imaginações sociológicas - no sentido dado por Mills (1982). Todavia, quando explicamos que não se trata de qualquer fotografia, mas, sim, de uma fotografia que enfoque os objetos a serem fotografados, eles se atrapalham, num primeiro momento, com o que exatamente deve ser 
fotografado. ${ }^{7}$ Por isso é essencial, junto a essa tarefa, trabalhar com a teoria. Uma vez explicitado tudo isso, a tarefa tornar-se-á mais fácil de ser realizada. Cabe dizer ainda que durante esse processo o uso de exemplos também ajuda os estudantes a entenderem exatamente o que precisa ser registrado nas fotografias: um arroio poluído, fumaça emitida pelo escapamento de veículos motorizados, a oxidação de portões ou grades de ferro, a água saindo de uma torneira, fios de alta tensão entrelaçados em galhos de árvores, um cachorro com coleira, uma flor em um vaso, etc. Nota-se que todos esses exemplos, além de cotidianos, são bastante simples, e justamente por isso não os percebemos, em um primeiro momento, como sendo retratos da interação entre Sociedade e Natureza.

Conforme já mencionado, experimentamos essa atividade em duas turmas de ensino técnico de uma instituição federal, durante o ano de 2018, na cidade de Porto Alegre. A primeira turma era de um curso noturno de Técnico em Administração na modalidade PROEJA, composta por 13 estudantes do sexo feminino com uma faixa etária variando entre 25 até mais de 60 anos de idade. Após explicar a atividade e solicitarmos as fotografias, obtivemos um resultado final bastante interessante, conforme podemos ver na prancha abaixo: ${ }^{8}$

\footnotetext{
7 Como diria Lenoble (1990), palavras que designam ideias muito gerais parecem claras quando as empregamos, todavia, quando refletimos sobre essas palavras, elas se tornam complexas e obscuras. Na ocasião o referido autor refletia sobre a palavra natureza e suas definições (LENOBLE, 1990).

${ }^{8}$ Vale dizer que as imagens, tanto da prancha 1, quanto da prancha 2, foram dispostas de forma aleatória, sem seguir nenhum modelo sequencial, estrutural ou de apresentação das fotografias (SAMAIN, 2000). Já a escolha das 24 fotografias para esse trabalho foi intuitiva e, olhando elas agora, talvez devido ao padrão de enquadramento.
} 
Prancha 1: Fotografias de uma turma de Técnico em Administraçãomodalidade PROEJA, sobre a interação entre Sociedade e Natureza
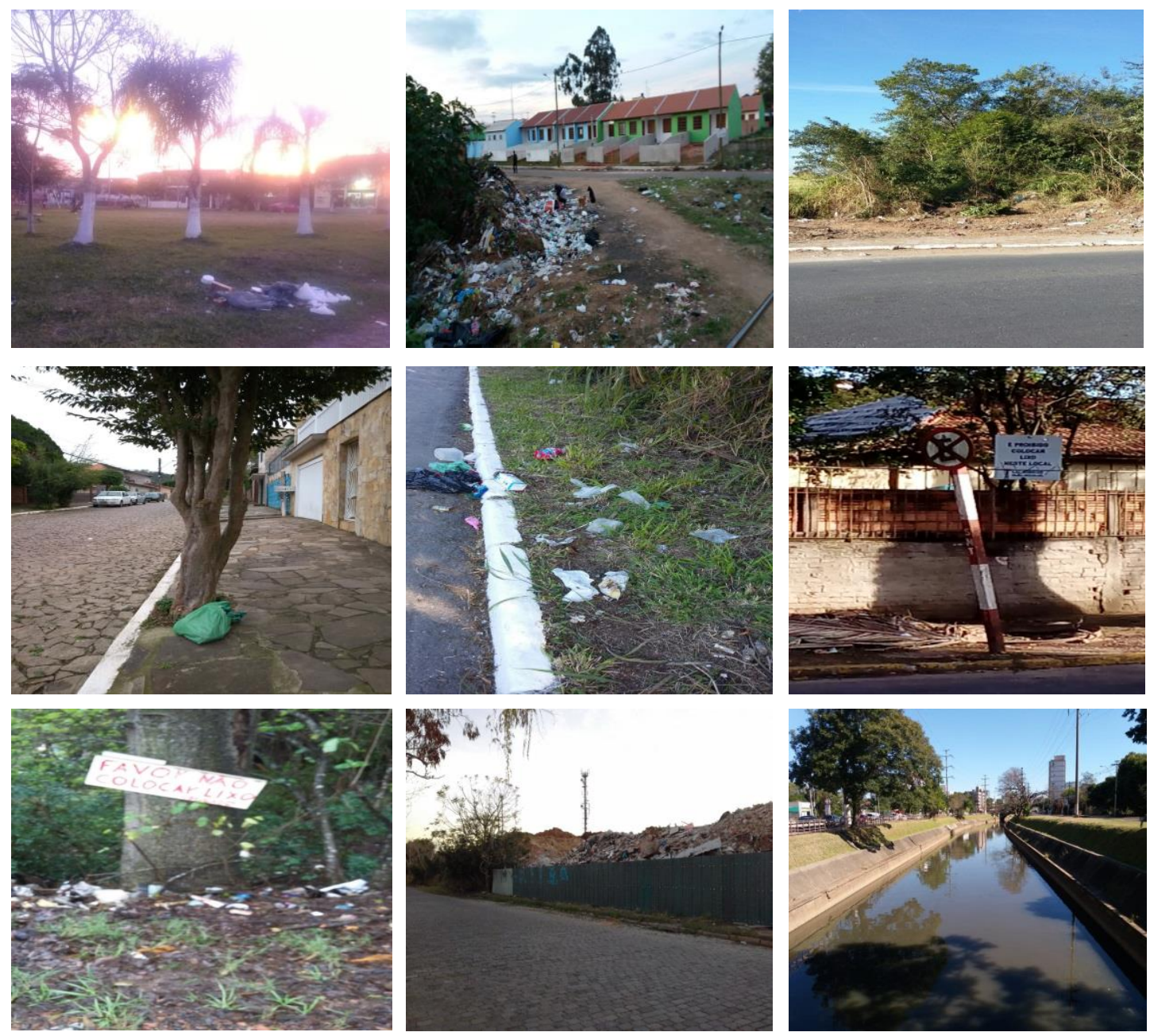

Fonte: Estudantes do Curso de Técnico em Administração- modalidade PROEJA, Porto Alegre, 2018.

Podemos observar nesse conjunto de imagens um padrão em que a maioria das fotografias registrou acúmulos de lixo jogados nas ruas ou em terrenos baldios e sempre próximos a algo que remetesse a ideia de Natureza, como árvores, um amontoado de mato ou um gramado. Isso demonstra que, talvez, a principal interação que essa turma percebeu entre um fenômeno social e um fenômeno ambiental tenha sido o descarte incorreto de lixo no meio ambiente e em locais 
tipicamente urbanos, e que tal situação seja corriqueira na vida dessas estudantes. Voltaremos a esse ponto mais adiante.

A segunda turma onde experimentamos a mesma atividade foi no curso de Técnico em Meio Ambiente, na mesma instituição, composta por 21 estudantes, de ambos os sexos, com uma faixa etária variando entre 18 até 58 anos de idade. Aqui também foi possível perceber um padrão nas fotografias, conforme podemos observar na prancha a seguir:

Prancha 2: Fotografias de uma turma de Técnico em Meio Ambiente, sobre a interação entre Sociedade e Natureza
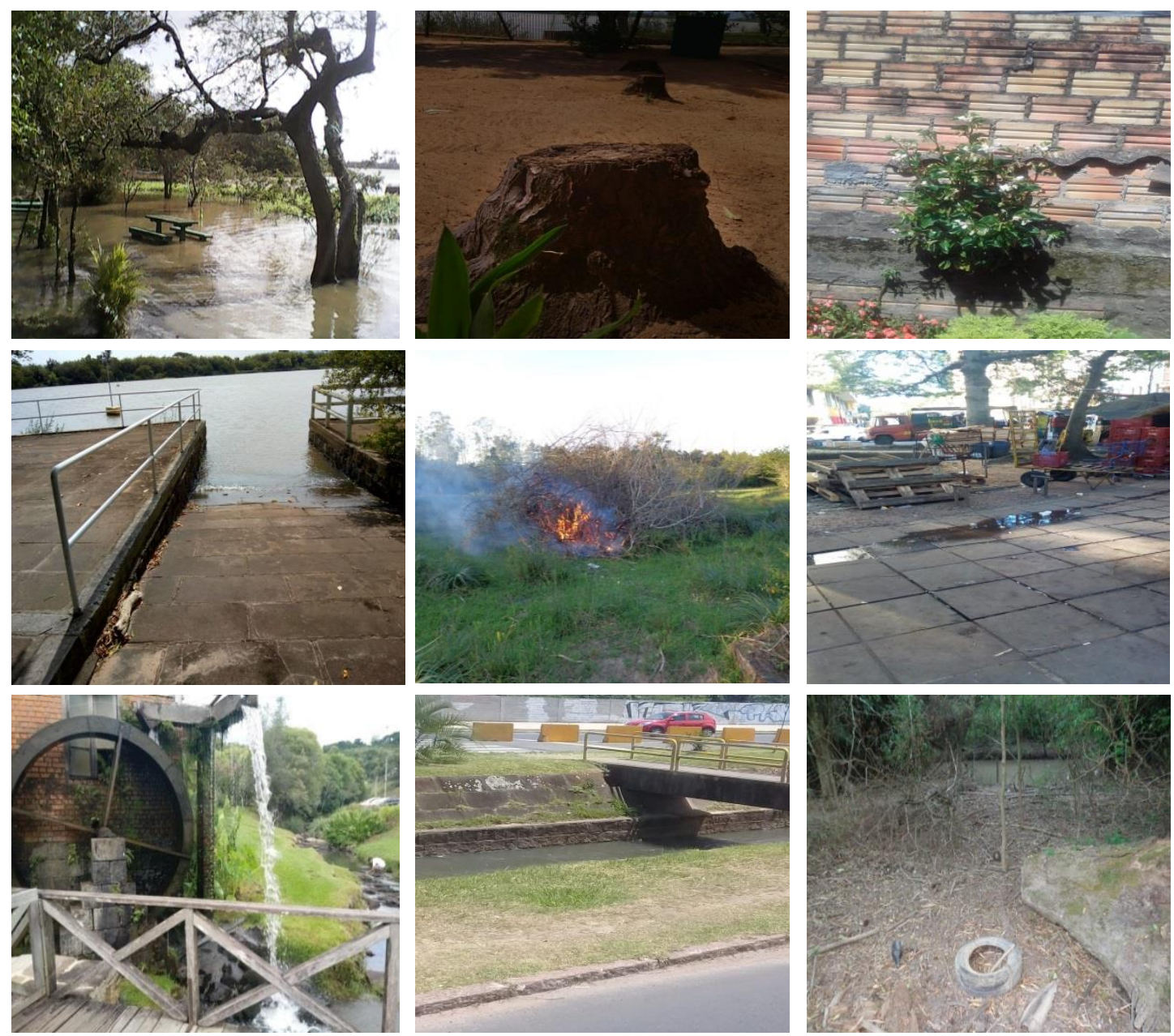

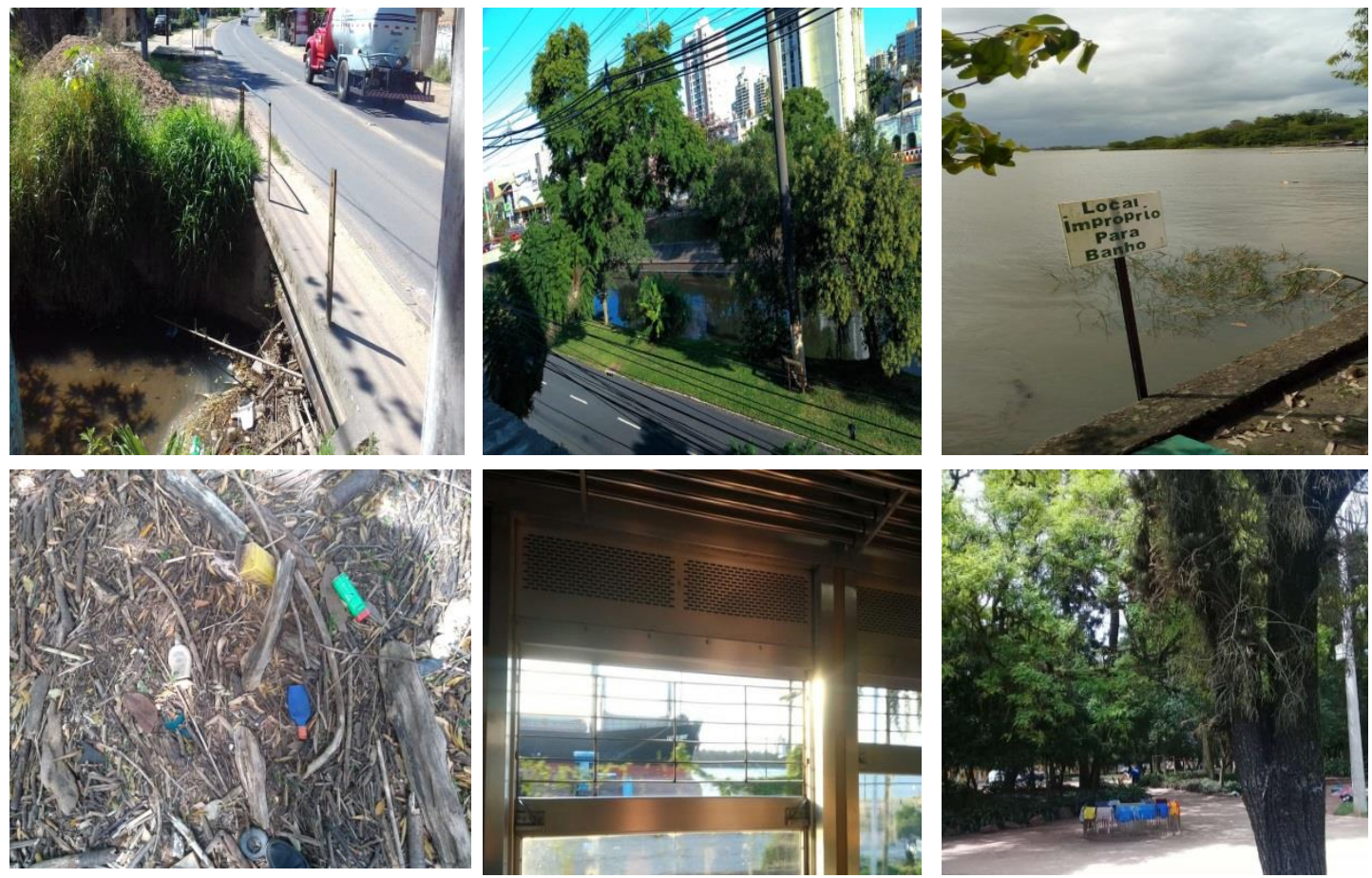

Fonte: Estudantes do Curso de Técnico em Meio Ambiente, Porto Alegre, 2018.

Ainda que a questão do lixo descartado de forma inadequada no meio ambiente não tenha sumido completamente das fotografias, percebemos que há nesse conjunto de fotos uma constância de imagens retratando o elemento Água. Talvez, esse padrão demonstre que a questão da poluição das águas seja - para essa turma em particular - um problema ambiental que reflete o impacto da Sociedade sobre o Meio Ambiente. Ademais, podemos observar que, tal como no primeiro conjunto de fotografias, a ideia de Natureza continua associada a elementos pertencentes ao Reino Vegetal (árvores, gramados, etc.).

Por fim, comparando os dois conjuntos de fotografias (pranchas 1 e 2), é interessante notar que em nenhum deles aparecem seres vivos, nem humanos e nem animais, ainda que todas as fotos retratem a presença da intervenção humana sobre o Meio Ambiente. Talvez, isso demonstre o quanto aquela visão antropocêntrica, da qual falávamos ainda há pouco, está enraizada na nossa forma de pensar a interação entre fenômenos sociais e fenômenos ambientais - forma essa que 
concebe os seres humanos como elementos apartados da Natureza e não integrados a ela, tal como um rio, uma árvore ou como um animal qualquer.

Para corroborar tal ideia, é interessante notar também que, mesmo em tempos de selfies, em nenhum momento os estudantes se fizeram notar enquanto sujeitos observadores dos objetos observados. Isto é, as imagens aqui retratadas, talvez devido ao padrão de enfoque distante, se mostraram impessoais e anônimas. Uma possível hipótese para isso é fato de que em nenhum momento foi explorada a capacidade técnica e/ou estética dos alunos e alunas na execução da tarefa solicitada. Podemos supor que, caso essas capacidades fossem estimuladas, eles e elas provavelmente apareceriam, de alguma forma, enquanto autores e autoras das fotografias no resultado final das imagens registradas.

Uma outra hipótese. Em termos psicanalíticos, poderíamos arriscar - e concordar com Freud - e afirmar que o ego tende a evitar, a se proteger e a se distanciar de tudo aquilo que represente um perigo externo para ele, visto que ameaças geram instintivamente ansiedades e medos nos indivíduos (FREUD, 1976). E sabemos que um dos principais riscos das sociedades contemporâneas é aquele representado pelas ameaças de degradação ambiental (BECK, 2011). Essa abordagem talvez possa explicar, também, o porquê de os estudantes permanecerem distantes nas imagens registradas por eles.

Voltando ao ponto de vista sociológico. Se por um lado os estudantes se mostraram "invisíveis" nas fotografias registradas - o quê não significa que eles estejam ausentes nelas, uma vez que o ato de ver, o olhar, carrega consigo pensamentos, ideias, conhecimentos, juízos, crenças, imaginações, fantasias, reflexões perspectivas, em suma, visões de mundo (CHAUI, 1988) próprias de cada indivíduo observador -, por outro lado podemos perceber nas imagens o momento sociohistórico 
que eles vivem: a capital gaúcha apresenta problemas de infraestrutura e de saneamento básico típicos dos grandes centros urbanos brasileiros. Conforme dados do Observatório da Cidade de Porto Alegre, no ano de 2010, o percentual de esgoto a céu aberto no entorno dos domicílios sobre o total de domicílios - era de $5 \%$, o que correspondia a 24.501 domicílios, e em algumas regiões da cidade esse valor era de $26 \%$. Ainda no ano de 2010, 6\% dos domicílios (29.175 domicílios) não possuíam ligação com rede de esgoto. Já, no ano de 2016, 24\% do total do esgoto gerado em de Porto Alegre não recebia nenhum tipo de tratamento, o que equivale 20.015.053 $\mathrm{m}^{3}$ de esgoto não tratado e, nesse mesmo ano, a perda de água no sistema de abastecimento foi de $18 \%$, ou $36.116 .901 \mathrm{~m}^{3}$ de água perdida. Voltado para o ano de 2010, apesar de a cidade garantir um destino adequado para praticamente todo lixo produzido (99\%), 6\% dos domicílios (28.466 domicílios) possuíam lixo acumulado no seu entorno, sendo que em algumas regiões da capital esse valor era de $38 \%$ (OBSERVAPOA, 200o). Convém lembrar ainda - para aqueles que não conhecem - que Porto Alegre é banhada por um lago historicamente marcado pelos elevados índices de poluição de suas águas e, além de ser um dos cartões-postais da cidade, ele está à vista para todos que chegam ou saem da capital gaúcha. Sendo assim, ainda que pouco subjetivas, as fotografias registradas pelos estudantes foram bastante objetivas na hora de captar e representar a realidade social e ambiental na qual eles estão inseridos.

\section{Considerações finais}

A atividade fotográfica descrita nesse trabalho não possui respostas certas ou erradas, pois, antes de tudo, tratou-se de uma experiência didática e, como tal, ela deve ser experimentada, testada e aperfeiçoada continuamente. Além disso, conforme dito no começo, essa 
atividade não se restringe à Sociologia, podendo ela ser aplicada em diferentes disciplinas, bem como em diferentes níveis de ensino.

Outro ponto que reforça o uso da fotografia e de registros fotográficos em sala de aula refere-se ao fato de que atualmente máquinas fotográficas estão ao alcance de quase todo mundo, sobretudo dos jovens, através dos aparelhos de telefone celular. Fato esse que torna o recurso fotográfico acessível e de fácil manuseio para os estudantes. Sem contar que as fotografias na era digital não acarretam maiores gastos econômicos e não necessitam de habilidade técnica, uma vez que os aparelhos de telefone celular, cada vez mais, possuem recursos quase dignos de uma câmera fotográfica profissional.

Além disso, o recurso fotográfico torna-se valioso como uma prática didática a ser empregada em sala de aula quando, ao invés de observarmos apenas uma fotografia, observamos um conjunto de registros fotográficos feito por diferentes fotógrafos/estudantes. Aqui, é possível extrairmos informações importantes para ensinar e para aprender questões relativas à interação entre os fenômenos sociais e os fenômenos ambientais. Pensemos, por exemplo, como conjuntos de fotografias podem variar de acordo com a idade, o nível escolar, a classe social, o cotidiano ou o local de moradia de diferentes grupos de estudantes. Sem dúvidas podemos extrair dessa diversidade diferentes formas de significados acerca da questão ambiental, bem como os modos que essa questão pode ser desnaturalizada e ressignificada em sala de aula.

Dessa breve explanação, concluímos que o uso de fotografias com um meio de apreensão e apresentação da Sociedade é um excelente recurso didático para o ensino e a aprendizagem de Sociologia em sala de aula, pois ela permite que, além de tornar os estudantes protagonistas ativos no processo de construção do conhecimento, eles imaginem sociologicamente. E sim, para concordarmos com Comenius, as imagens 
são extremamente agradáveis de serem observadas e interpretadas. Todavia, isso não é válido apenas para os estudantes, mas, também, para os professores.

\section{REFERÊNCIAS}

AGENCIA NACIONAL DE TELECOMUNICAÇÕES. Dados, Telefonia Móvel - Acessos. Acessos dos Serviços Móveis Pessoais, Agosto de 2018, Brasil, 2018. Disponível em: http://www.anatel.gov.br/dados/acessos-telefonia-movel. Acesso em 28 de outubro de 2018.

ALONSO, Angela; COSTA, Valeriano. Ciências Sociais e Meio Ambiente no Brasil: um balanço bibliográfico. BIB - Revista Brasileira de Informações Bibliográficas em Ciências Sociais, São Paulo, ANPOCS, n. 53, 1ำ sem., 2002, p. 35-78.

BAUMAN, Zigmunt; MAY, Tim. Aprendendo a Pensar com a Sociologia. Rio de Janeiro: Zahar, 2010.

BECK, Ulrich. Sociedade de Risco: rumo a uma outra modernidade. São Paulo: Editora 34, 2011.

BECKER, Howard Saul. Falando da Sociedade: ensaios sobre as diferentes maneirais de representar o social. Rio de Janeiro: Jorge Zahar , 2009 .

BENJAMIN, Walter. Pequena História da Fotografia. In: . Magia e técnica, arte e política: ensaios sobre literatura e a história da cultura. Obras Escolhidas, vol. 1. São Paulo: Editora Brasiliense, 1987, p. 91-107.

BODART, Cristiano das Neves. Fotografia como recurso didático no ensino de sociologia. Em Tese, Florianópolis, PPGSP/UFSC, v. 12, n. 2, ago./dez., 2015, p. 81-101.

BOURDIEU, Pierre Un Arte Medio: ensayo sobre los usos sociales de la fotografia. Barcelona: Editorial Gustavo Gili, 2003.

; BOURDIEU, Marie-Claire. O Camponês e a Fotografia. Rev.

Sociologia Política, Curitiba, v. 26, 2006, p. 31-39. 
BRASIL. Lei nº 9.795, de 27 de Abril de 1999. Dispõe sobre a educação ambiental, institui a Política Nacional de Educação Ambiental e dá outras providências. Brasília, Diário Oficial - Imprensa Nacional, 1999.

. Ministério da Educação, Secretaria de Educação Básica. Ciências humanas e suas tecnologias. In: Orientações curriculares para o Ensino Médio - volume 3. Brasília, 2006.

Ministério da Educação, Conselho Nacional de Educação, Conselho Pleno. Resolução no 2, de 15 de Junho de 2012. Estabelece as Diretrizes Curriculares Nacionais para a Educação Ambiental. Brasília, 2012.

Ministério da Educação, Conselho Nacional de Educação, Câmara de Educação Básica. Resolução no 2, de 30 de Janeiro 2012. Define Diretrizes Curriculares Nacionais para o Ensino Médio. Brasília, Diário Oficial da União, 2012a.

BUTTEL, Frederick Howard. A Sociologia e o Meio Ambiente: um caminho tortuoso rumo à Ecologia Humana. Perspectiva, São Paulo, v. 15, 1992, p. 69-94.

CATTON, Willian Robert Jr.; DUNLAP, Riley. Environmental Sociology: a new paradigm. The American Sociologist, United States, v. 13, n. 1, 1978, p. 4-49.

CHAUI, Marilena. Janela da Alma, Espelho do Mundo. In: ADAUTO, Novaes Adauto (org.). O Olhar. São Paulo: Companhia das Letras, 1988, p. 31-64.

COMENIUS, John Amos. The Orbis Pictus. New York: C.W. Bardeen Publisher, 1887.

CUSICANQUI, Silvia Riveira. Sociología de la imagem: Mirandas ch’ixi desde la historia andiana. Bueno Aires: Tinta Limón, 2015.

FERNANDES, Maria Esther. Imagem e Olhar em Pesquisa: para além do visível. Revista Hospitalidade, São Paulo, v. VIII, n. 2, jul./dez., 2011, p. 38-51.

FERREIRA, Leila da Costa; FERREIRA, Lúcia da Costa. Águas Revoltas: um balanço provisório da Sociologia Ambiental no Brasil. BIB - Revista 
Brasileira de Informações Bibliográficas em Ciências Sociais, São Paulo, n. 54, 20 sem., 2002, p. 83-100.

FERRO, Lígia. Ao Encontro da Sociologia Visual. Rev. da Faculdade de Letras da Universidade do Porto, Porto, n. 15, 2015, p.373-398.

FREUD, Sigmund. Um Estudo Autobiográfico, Inibições, Sintomas e Ansiedade, A Questão da Análise Leiga e Outros Trabalhos: Edição standard brasileira das obras psicológicas completas de Sigmund Freud (Vol. 20). Rio de Janeiro: Imago, 1976.

FREUND, Gisèle. La Fotografia como documento social. Barcelona: Editorial Gustavo Gili, 1993.

HERCULANO, Selene. Sociologia Ambiental: origens, enfoques metodológicos e objetos. Rev. Mundo e Vida: alternativas em estudos ambientais, Rio de Janeiro, UFF/PGCA-Riocor, n. 1, Ano 1, 2000, p. 45-55.

INSTITUTO BRASILEIRO DE GEOGRAFIA E ESTATÍSTICA. População Projeções e estimativas da população do Brasil e das Unidades da Federação, 2018. Disponível em: https://www.ibge.gov.br/apps/populacao/projecao//index.html. Acesso em 28 de Outubro de 2018.

LENOBLE, Robert. História da Ideia de Natureza. Lisboa: Edições 70, 1990.

MARTINS, José de Souza. Sociologia da Fotografia e da Imagem. São Paulo: Contexto, 2009.

MILLS, Charles, Wright. A Imaginação Sociológica. Rio de Janeiro: Zahar, 1982.

OBSERVATÓRIO DA CIDADE DE PORTO ALEGRE - ObservaPOA. Indicadores. Porto Alegre em Análise, Sistema de Gestão e Análise de Indicadores, Porto Alegre, 200o. Disponível em: $<$ http://portoalegreemanalise.procempa.com.br/?analises=o_o_o > . Acesso em: 22 de Maio de 2019.

SAMAIM, Etienne. Os riscos do texto e da imagem - Em torno de Balinese character (1942), de Gregory Bateson e Margaret Mead. Revista Brasileira de Semiótica, São Paulo, n. 14, 2000, p. 20-37. 